\title{
Produtividade do tomateiro em casa de vegetação com diferentes graus tecnológicos.
}

\section{Jaques B. de Jesus Junior*, Thais Q. Z. Cesar}

\section{Resumo}

O projeto consistiu em avaliar o desenvolvimento de mudas e plantas de tomateiro cultivadas em casas-de-vegetação com diferentes graus tecnológicos. O primeiro cenário (CV1) possuía ventilação natural, laterais com tela anti-afídeo e cobertura com plástico difusor novo. O segundo (CV2) possuía ventilação natural, laterais com tela anti-afídeo, cobertura com plástico difusor novo e tela vermelha $80 \%$. Por fim, o terceiro (CV3) possuía ventilação mecânica, cobertura e laterais com plástico difusor com mais de cinco anos de uso. Assim, foram distribuídas duas cultivares de tomate ('Santa Clara 5800' e 'Santa Cruz Kada Gigante') em cada casa-de-vegetação e, em seguida, avaliado o desempenho das mesmas em função da taxa de emergência, dos atributos das mudas, da parte aérea das plantas e das raízes. Constatou-se que o segundo cenário, em magnitude, favoreceu a taxa de emergência, o crescimento das mudas e o crescimento das plantas, para ambas as cultivares estudadas.

\section{Palavras-chave:}

Ambiência, tela vermelha, ventilação natural.

\section{Introdução}

O Brasil é um dos maiores produtores mundiais de tomate de mesa (MAPA, 2011). Diversos trabalhos têm utilizado essa cultura para estudo em casa de vegetação, dada sua importância: Com isso, o projeto objetivou avaliar o desenvolvimento de mudas e das plantas de tomateiro cultivadas em casas-de-vegetação com diferentes graus tecnológicos.

\section{Resultados e Discussão}

A figura 1 mostra os resultados das taxas de emergência em cada casa de vegetação e para cada cultivar avaliada. Observa-se que, em magnitude, a casa de vegetação CV2, apresentou os melhores resultados, seguido da casa de vegetação CV3.

Figura 1. Taxa de emergência para mudas de tomate cultivadas em diferentes casas-de-vegetação.

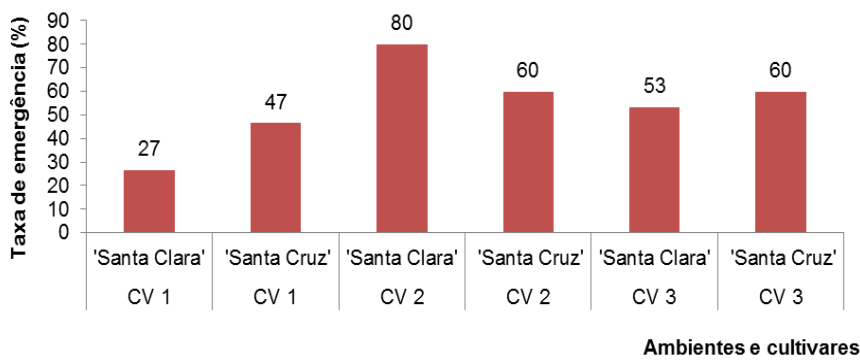

A tabela 1 mostra os resultados das análises das mudas, aos 46 dias após a semeadura. Observa-se que, em magnitude, os melhores resultados de altura da planta foram obtidos na casa de vegetação $\mathrm{CV} 2$, e os menores resultados obtidos na CV1.

Tabela 1. Análise das mudas de tomate cultivadas em diferentes casas-de-vegetação.

\begin{tabular}{ccccc}
\hline & Tratamento & Altura [cm] & Diâmetro [mm] & $\mathrm{n}^{0}$ folhas \\
\hline CV 1 & 'Santa Clara' & 19,38 & 4,41 & 5,25 \\
& 'Santa Cruz' & 15,71 & 4,03 & 4,00 \\
CV 2 & 'Santa Clara' & $\mathbf{2 7 , 2 5}$ & 4,15 & 4,67 \\
& 'Santa Cruz' & $\mathbf{2 0 , 9 4}$ & 4,00 & 3,88 \\
CV 3 & 'Santa Clara' & 22,50 & 4,58 & 4,88 \\
& 'Santa Cruz' & 18,31 & 4,39 & 4,25 \\
\hline
\end{tabular}

A tabela 2 mostra os resultados das análises da parte aérea das plantas, aos 61 dias após a semeadura. Observa-se que, em magnitude, os melhores resultados de massa e do comprimento da parte aérea fresca foram obtidos na casa de vegetação CV2 e os menores resultados obtidos na CV1.

Tabela 2. Análise da parte aérea das plantas de tomate cultivadas em diferentes casas-de-vegetação.

\begin{tabular}{cccccc}
\hline \multicolumn{2}{c}{ Tratamento } & M fresca [g] & M seca [g] & Comprimento [cm] & n $^{0}$ folhas \\
\hline \multirow{2}{*}{ CV 1. } & 'Santa Clara' & 25,64 & 2,63 & 38,10 & 8,75 \\
& 'Santa Cruz' & 18,88 & 1,90 & 34,70 & 7,75 \\
CV 2. & 'Santa Clara' & $\mathbf{2 9 , 8 0}$ & 2,80 & $\mathbf{5 1 , 3 3}$ & 8,00 \\
& 'Santa Cruz' & $\mathbf{2 6 , 5 7}$ & 2,46 & $\mathbf{5 0 , 8 0}$ & 9,75 \\
CV 3 & 'Santa Clara' & 23,19 & 2,61 & 41,90 & 8,50 \\
& 'Santa Cruz' & 20,37 & 2,17 & 37,05 & 7,75 \\
\hline
\end{tabular}

A tabela 3 mostra os resultados das análises das raízes, aos 61 dias após a semeadura. Observa-se que, em magnitude, os resultados máximo e mínimo de massa e do comprimento da parte radicular fresca foram obtidos na casa de vegetação CV1, para a cultivar Santa Clara e para a cultivar Santa Cruz, respectivamente.

Tabela 3. Análise das raízes das plantas de tomate cultivadas em diferentes casas-de-vegetação.

\begin{tabular}{ccccc}
\hline \multicolumn{2}{c}{ Tratamento } & M fresca [g] & M seca [g] & Comprimento [cm] \\
\hline CV 1 & 'Santa Clara' & $\mathbf{5 , 5 9}$ & 0,25 & $\mathbf{3 9 , 0 8}$ \\
& 'Santa Cruz' & 3,08 & 0,03 & 21,13 \\
CV 2 & 'Santa Clara' & 4,32 & 0,02 & 30,10 \\
& 'Santa Cruz' & 3,75 & 0,06 & 31,93 \\
CV 3 & 'Santa Clara' & 4,74 & 0,14 & 25,98 \\
& 'Santa Cruz' & 4,72 & 0,11 & 23,48 \\
\hline
\end{tabular}

\section{Conclusões}

Em magnitude, o segundo cenário favoreceu a taxa de emergência, o crescimento das mudas (em altura) e das plantas (massa e comprimento da parte aérea fresca), para ambas as cultivares Santa Clara e Santa Cruz.

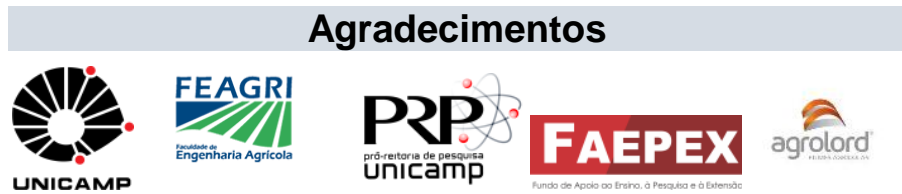

\footnotetext{
${ }^{1}$ MAPA - Ministério da Agricultura Pecuária e Abastecimento. Norma para produção integrada de tomate é debatida. 2011.
} 